\title{
Effect of diamond particles on the microstructure and composition of pulse plated multilayer Ni-W/diamond composite coatings
}

\author{
Malay Kumar Das ${ }^{1, *}$, Jiaqian Qin², and Priya $\mathrm{Karn}^{3,4}$ \\ ${ }^{1}$ International graduate program of Nano-science and technology, Chulalongkorn University, \\ Bangkok 10330 Thailand \\ ${ }^{2}$ Metallurgy and materials science research institute, Chulalongkorn University, Bangkok 10330, \\ Thailand \\ ${ }^{3}$ Institute of Engineering- Tribhuvan University Purwanchal campus, Dharan, Nepal \\ ${ }^{4}$ PAVIMAM Solutions Education and Research Center of Excellence, India
}

\begin{abstract}
The research encompasses the fabrication of multilayer Ni-Wdiamond composite deposits by pulse current electrodeposition. The mean surface diameter of the diamond used for the research was 0.9 microns. The composites were fabricated under various conditions and characterized by means of SEM, EDS and XRD to investigate and analyze their microstructure, grain size and elemental distribution along with variations in morphology under different conditions. The effect of variations in forward and reverse current density along with duty cycle and the combination of various aforesaid conditions on the coatings were studied and analyzed.
\end{abstract}

\section{Introduction}

Nanocrystalline Ni-W alloys and composites have a wide arrays of applications such as fabricating the alloys in some sort of barrier/capping layers for ultra large scale integration applications in copper metallization and also potential applications in Microelectromechanical systems and also various allied applications in mold inserts, magnetic heads and relays, bearings, resistors, electrodes accelerating hydrogen evolution from alkaline solutions, environmentally safe substitute for hard chromium plating in the aerospace industry, etc.[1]. Hard-chrome plating has been used as a surface finishing technique in various engineering industries because it has good advantages such as high hardness, corrosion resistance, wear resistance, aesthetic qualities and durability. However, Hard-chrome plating solutions are toxic, carcinogenic and hazardous to human health $[2,3]$ to substitute chromium; the new alternate surface finishing method must maintain hardchrome's advantages. One very important and sustainable prospect is to substitute HardChrome plating with metal alloys/composites plating which is certainly better than plating metals with alloys as alloys and composite plating directly on a suitable substrate tends to enhance the abrasion resistance and resistance to surface erosion phenomena while on the

*Corresponding author: malaykumardas90@gmail.com 
other hand acts as a highly viable and suitable substitute to hard chrome plating[2]. In various industrial applications (for example boilers) it has been documented that the surface of the equipment and components involved in the running of the plant are highly to prone to mechanical stress, corrosion and damage by wear. This in turn leads to plant closures and subsequent loss in revenue and operations in related industries like mining, mineral processing etc. Hence it becomes imperative to work upon strategies to enhance the surface properties rather than bulk properties [4-6] in a wide scope of engineering materials and components used in industries. It is also an interesting prospect to try and introduce various composites

$\mathrm{Ni}-\mathrm{W} /$ diamond composite coatings were electrodeposited by means of pulse plating on a $2 * 2$ carbon steel substrate. The operating conditions were modified to obtain a multilayer electrodeposited coating of varying properties, thickness, composition and attributes constituting the aforesaid composites. Diamond composite incorporation into the NickelTungsten alloy matrix could significantly enhance the mechanical properties of the Ni-W base coated matrix in terms of hardness[7], wear resistance, corrosion resistance, abrasion resistance, increased durability, thermal resistance and also the overall roughness of the coatings. However, the major issue that needs to be fixed before embarking on the fabrication of multilayer coatings is to ensure the uniform distribution of diamond particles on the coated matrix. Various contemporary researchers have employed the means of pulse plating to fabricate ni-w and other alloys and composites[8]. Employing suitable pulse parameters is quite crucial to obtain desirable deposits. Fabrication of Multilayer coatings also enhance the versatility of the deposits in terms of varying layers of different surface roughness, friction and wear resistance along with hardness. The influence on the microstructure of a multilayer coating is also profound and very important in terms of enhancement of film structure and quality.

\section{Experimental details}

Ni-W-diamond composites were fabricated by means of electrodeposition from an ammonia-citrate bath $(200 \mathrm{ml})$ on a $2 * 2$ steel substrate. The bath composition was nickel sulphate $15.8 \mathrm{~g} / \mathrm{l}$, sodium tungstate $46.20 \mathrm{~g} / \mathrm{l}$, tri-sodium citrate $147 \mathrm{~g} / \mathrm{l}$, ammonium chloride $26.7 \mathrm{~g} / 1$ and sodium bromide $15.8 \mathrm{~g} / 1$ respectively. The operating temperature was $75^{\circ} \mathrm{C}$ the $\mathrm{pH}, 200 \mathrm{RPM}$ stirring speed and the deposition time was kept constant at $200 \mathrm{RPM}$ and 2 hours, respectively. X-Ray Diffraction technique was employed to analyze crystalline size of the coatings. Brooker D8 advance X-ray diffractometer operated at $\mathrm{Cu} \mathrm{K} \alpha$ radiation (nickel filtered) at a rating of $40 \mathrm{kV}, 20 \mathrm{~mA}$. The scan rate was $0.02 \circ$ per step and the measuring time $0.5 \mathrm{~second} / \mathrm{step}$. Scherrer's equation[9] was employed for the calculation of the grain size of the electrodeposited crystals. The samples were characterized in terms of morphology and microstructure by JEOL JSM-6400 SEM with EDS capability embedded into it.

\subsection{Pulse parameters}

Table 1. Pulse parameters for the experiments.

\begin{tabular}{|c|c|c|c|c|c|c|}
\hline Sample & $\begin{array}{c}\text { Diamond } \\
\text { Concentratio } \\
\mathrm{n} \\
(\mathrm{g} / \mathrm{l})\end{array}$ & $\begin{array}{c}\text { Forward } \\
\text { Current } \\
\text { Density } \\
\mathrm{A} / \mathrm{cm}^{2}\end{array}$ & $\begin{array}{c}\text { Forward } \\
\text { Duration } \\
(\mathrm{ms})\end{array}$ & $\begin{array}{c}\text { Reverse } \\
\text { Current } \\
\text { Density } \\
\mathrm{A} / \mathrm{cm}^{2}\end{array}$ & $\begin{array}{c}\text { Reverse } \\
\text { Duration } \\
(\mathrm{ms})\end{array}$ & $\begin{array}{c}\text { Duration } \\
\text { of Each } \\
\text { Layer } \\
\text { (minutes } \\
)\end{array}$ \\
\hline $\mathrm{A}$ & 5 & 0.2 & 20 & 0.3 & 3 & - \\
\hline $\mathrm{B}$ & 5 & 0.2 & 20 & 0.15 & 2 & - \\
\hline
\end{tabular}




\begin{tabular}{|c|c|c|c|c|c|c|}
\hline C & 5 & 0.2 & 20 & 0 & 3 & - \\
\hline D & 5 & 0.2 & 20 & 0 & 0 & - \\
\hline A_ND & 0 & 0.2 & 20 & 0.3 & 3 & - \\
\hline AB_0.1 & 5 & $\mathrm{~A}=0.2$ & $\mathrm{~A}=20$ & $\mathrm{~A}=0.3$ & $\mathrm{~A}=3$ & $\mathrm{~A}=0.1$ \\
& & $\mathrm{~B}=0.2$ & $\mathrm{~B}=20$ & $\mathrm{~B}=0.15$ & $\mathrm{~B}=3$ & $\mathrm{~B}=0.1$ \\
\hline AC_0.1 & 5 & $\mathrm{~A}=0.2$ & $\mathrm{~A}=20$ & $\mathrm{~A}=0.3$ & $\mathrm{~A}=3$ & $\mathrm{~A}=0.1$ \\
& & $\mathrm{C}=0.2$ & $\mathrm{C}=20$ & $\mathrm{C}=0$ & $\mathrm{C}=3$ & $\mathrm{C}=0.1$ \\
\hline AD_0.1 & 5 & $\mathrm{~A}=0.2$ & $\mathrm{~A}=20$ & $\mathrm{~A}=0.3$ & $\mathrm{~A}=3$ & $\mathrm{~A}=0.1$ \\
& & $\mathrm{D}=0.2$ & $\mathrm{D}=2$ & $\mathrm{D}=0$ & $\mathrm{D}=0$ & $\mathrm{C}=0.1$ \\
\hline AC_1 & 5 & $\mathrm{~A}=0.2$ & $\mathrm{~A}=20$ & $\mathrm{~A}=0.3$ & $\mathrm{~A}=3$ & $\mathrm{~A}=1$ \\
& & $\mathrm{C}=0.2$ & $\mathrm{C}=20$ & $\mathrm{C}=0$ & $\mathrm{C}=3$ & $\mathrm{C}=1$ \\
\hline AC_2 & 5 & $\mathrm{~A}=0.2$ & $\mathrm{~A}=20$ & $\mathrm{~A}=0.3$ & $\mathrm{~A}=3$ & $\mathrm{~A}=2$ \\
& & $\mathrm{C}=0.2$ & $\mathrm{C}=20$ & $\mathrm{C}=0$ & $\mathrm{C}=3$ & $\mathrm{C}=2$ \\
\hline
\end{tabular}

\section{Results}

\subsection{Grain size}

Upon analyzing the grain size, a progressive reduction in grain size is observed from A to D. For the Multilayer AD has the optimal size of $7 \mathrm{~nm}$ whereas grain size is subsequently enlarged in case of $\mathrm{AB}$ and $\mathrm{AC}$ with each alternating layer deposited for 0.1 minutes respectively. The incorporation of diamond composites into the alloy matrix/grains increases the grain size from 18 to $23 \mathrm{~nm}$. Therefore, the incorporation of diamond particles into the coating matrix is subsequently established. It is clear that the diamond particles have been embedded into the coating matrix by means of a chemical bonding with the base alloy matrix and not merely by means of physical adhesion or mechanical cohesion. This is a relevant result to further study the means to enhance the level of incorporation of diamond particles and the distribution of diamond particles in the coatings.

Table 2. Grain size of the coatings.

\begin{tabular}{|c|c|}
\hline Sample & Grain size(nm) \\
\hline A_ND & 18 \\
\hline A & 23 \\
\hline B & 19 \\
\hline C & 4 \\
\hline D & 5 \\
\hline AB_0.1 & 16 \\
\hline AC_0.1 & 8 \\
\hline AD_0.1 & 7 \\
\hline
\end{tabular}

\subsection{SEM and EDS analysis}

Comparative analysis for figure 1 and 2 reveals the morphological differences between the samples with and without diamond addition[10]. This reveals the importance and the indispensability of diamond composites addition in the Nickel-Tungsten. There is a marked difference in the microstructure for samples with and without diamond addition. Figure 1 depicts a uniform film structure and distribution of diamond particles. Moreover, there are no cracks and pit formations in the samples containing diamond composites encapsulated into the matrix. Unlike the former the samples without diamond have a lot of quasi circular formations for almost all magnifications. There seems to be a lot of pit formations in all of the images without diamond. There is a clear evidence of numerous cracks and fissures on the microstructure for fig. 2 (b). The coating is discontinuous with evidence of internal 
strain which causes cracks and lack of continuity and uniformity in the film thereby severely affecting the microstructure and in turn the properties associated with them. The coatings with diamond reveal uniform crystalline formations also with no sharp grain boundaries unlike the samples without diamond which has highly discontinuous formations on the surface with no uniformity in terms of deposition and film quality. The comparison between the morphologies of Figure 1 and 2 clearly established the need for use of diamond composites in Ni-W alloy matrix in order to enhance the properties of the coatings. This is a very relevant and substantial result in terms of our justifications for the use of the diamond particles as composites in the coating matrix.

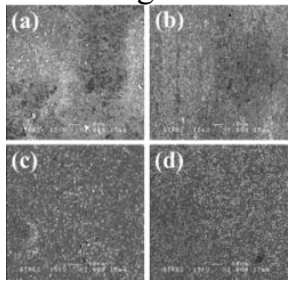

Fig. 1. SEM Images of (a) A monolayer layer (b) B monolayer (c) C monolayer (d) D monolayer.

Figure 2 depicts the SEM images for the Multilayer coating AB_0.1, AC_0.1 and AD_0.1. The image 3 (b) exhibits stark differences in terms of distribution of diamond particles, cracks and irregularity in crystal structure. The pairs AB_0.1 and AD_0.1 are similar and have a uniform crystal structure. The important results that is evident from Figure 3 is that the while fabrication of multilayer AC layer is not desirable in terms of morphology and microstructure. Therefore, either $\mathrm{AB}$ or $\mathrm{AD}$ should be used a template layer for fabrication of multilayer Ni-W-Diamond.

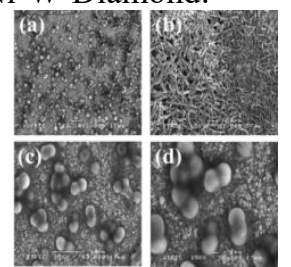

Fig. 2. SEM Images for A layer without diamond (a) for 1000X (b) for 2000X (c) for 3000X (d) for $5000 \mathrm{X}$.

The diamond content in the coatings of AC_0.1 also appears to be considerably lesser than both $\mathrm{AB} \_0.1$ and $\mathrm{AD} \_0.1$. However, upon close analysis it is revealed that the surface contamination is greater in case of $\mathrm{AB} \_0.1$ as compared to $\mathrm{AD}_{-} 0.1$, an idea which is corroborated by the presence of a large number of white spots which are most likely to be oxygen and carbon contaminates encapsulated into the coating during the deposition process. The SEM analysis acts as an important tool to identify and ascertain the optimal and suitable conditions for the NI-W-diamond coatings.
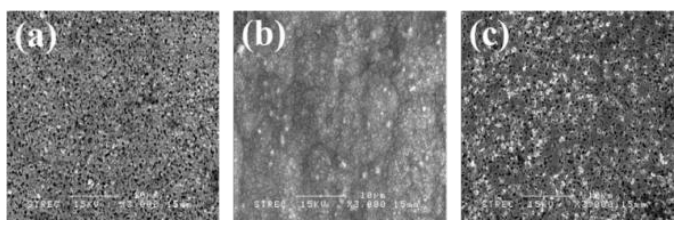

Fig. 3. SEM Images for (a) AB_0.1 (b) AC_0.1 (c) AD_0.1.

\subsection{EDS analysis}


Table 3. Elemental composition of $\mathrm{Ni}$ and $\mathrm{W}$ in the deposits as reported by the EDS results.

\begin{tabular}{|c|c|c|}
\hline Sample & Ni (At \%) & W (At \%) \\
\hline A ND & 95.42 & 4.58 \\
\hline A & 99.06 & 0.94 \\
\hline B & 97.62 & 2.38 \\
\hline C & 78.58 & 21.42 \\
\hline DB_0.1 & 85.56 & 14.44 \\
\hline AC_0.1 & 92.97 & 7.03 \\
\hline AD_0.1 & 82.87 & 17.13 \\
\hline
\end{tabular}

The EDS results suggest enhanced Tungsten content in the AD_0.1 layer. This is possibly because $\mathrm{D}$ is the direct current which allows for an enhanced duty cycle and thereby and enhanced plating rate leading to a higher co-deposition of tungsten. However, the Tungsten Content decreases drastically when diamond is added to the A layer. This is due to the encapsulation of diamond particles into the coating matrix. The carbon content results in the EDS analysis might also contain carbon contaminates on the coated surface which is why the diamond content by weight in the coatings needs to be investigated by dissolving the coating and the entire substrate in iron and in turn measuring the difference in weight to give the diamond content.

\subsection{Relationship between Grain Size and Tungsten content}

Table 4 shows a clear relationship between grain size and tungsten content wherein the smaller grain size facilitates an increased concentration of tungsten in most cases. Upon analysis of AD_0.1, A_ $0.1, \mathrm{C}$ and $\mathrm{D}$ it's clear that a smaller grain size enables more codeposition of tungsten in the coated matrix thereby enhancing the tungsten content in the deposits. However, the nature of the current that causes the deposition is also an important factor to determine the tungsten content in the coating which is evident from the fact that the samples AD_0.1 which has D layer as direct current deposited layer has the highest tungsten content among all the coated layers. However, the tungsten content probably follows a limiting value of grain size beyond which tends to violate the aforesaid trend which is why a very reduced tungsten content is observed in case of single layers $\mathrm{A}, \mathrm{B}, \mathrm{C}$ and D and also in case of A_ND layer without diamond. The substantial reduction in grain size for the A single layer without diamond and with diamond can also be credited to the fact that diamond encapsulation into the base matrix tends to reduce the tungsten content. The SEM images as in Fig. 1 and 2 along with the relative data of tungsten content reduction and grain size increment can be used as arguments to prove that diamond has been embedded into the coatings uniformly and not mere weak physical adhesion or mechanical cohesion.

Table 4. Grain Size and Tungsten Content comparison for various conditions.

\begin{tabular}{|c|c|c|}
\hline Layer Conditions & Grain Size(nm) & W (At \%) \\
\hline A_ND & 18 & 4.58 \\
\hline A & 23.1 & 0.94 \\
\hline B & 19.1 & 2.38 \\
\hline C & 4.1 & 21.42 \\
\hline D & 5.1 & 14.44 \\
\hline AB_0.1 & 16.5 & 7.03 \\
\hline AC_0.1 & 8.4 & 17.13 \\
\hline AD_0.1 & 7 & 24.25 \\
\hline
\end{tabular}




\section{Conclusion}

AD_0.1 has an optimal grain size of $7 \mathrm{~nm}$ and the most suitable SEM morphology in terms of uniform distribution of diamond particles, film quality, finer grain size and less pronounced grain boundaries as compared to $\mathrm{AB}$ and $\mathrm{AC} 0.1 \mathrm{~min}$ multilayer deposits. There are also almost nil cracks as per SEM morphology for AD_0.1 and AB_0.1 unlike AC 0.1

The incorporation of diamond is meagre, and the distribution also not uniform in the case of AC_0.1. AC_0.1 layer also doesn't have the most suitable grain size, or the tungsten content as compared to AD_0.1layer.

The tungsten content is the maximum in case of $\mathrm{AD}$-0.1 layer and it is the most desirable in terms of both SEM morphology and grain size. However, the actual values of diamond content in the deposits along with various other mechanical properties namely hardness, wear and corrosion resistance need to be figured out before attributing it as the most suitable condition for multilayer. Smaller grain size and suitable layer conditions facilitate larger deposition rate of tungsten in the coatings and an overall increased tungsten content as per EDS results.

\section{References}

1. Eliaz, N., T. Sridhar, and E. Gileadi, Synthesis and characterization of nickel tungsten alloys by electrodeposition. Electrochimica Acta, 2005. 50(14): p. 2893-2904.

2. Xiaohe, W. and X.B.-s.H. Zhen-feng, Progress in developing electrodeposition for substitute hard chromiumll. New Technology and New Process, 2009.

3. Nagai, T., K. Hodouchi, and H. Matsubara, Relationship between film composition and microhardness of electrodeposited Ni-W-B films prepared using a citrate-glycinate bath. Surface and Coatings Technology, 2014. 253(0): p. 109-114.

4. Shang, Y.-L., et al., Electrorheological property of M-doped ( $\mathrm{M}=\mathrm{Na}, \mathrm{Zr})$ nano-sized TiO2 particle materials, influence of surface composition and microstructure. Colloids and Surfaces A: Physicochemical and Engineering Aspects, 2008. 325(3): p. 160-165.

5. An, Y.-1., et al., Interfacial structure and mechanical properties of surface iron-nickel alloying layer in pure iron fabricated by surface mechanical attrition alloy treatment. Materials \& Design, 2013. 46(0): p. 627-633.

6. Krauss, G., Advanced surface modification of steels. Journal of Heat Treating, 1992. 9(2): p. 81-89.

7. Yuan Xuetao, W.Y., Sun Dongbai, Yu Hongying, Influence of pulse parameters on the microstructure and microhardness of nickel electrodeposits. Surface \& Coatings Technology, 2008. 202: p. 1895-1903.

8. El-Sherik, A.M., U. Erb, and J. Page, Microstructural evolution in pulse plated nickel electrodeposits. Surface and Coatings Technology, 1997. 88(1-3): p. 70-78.

9. B.D.Cullity, S.R.S., S.Stock, ElementsofX-rayDiffraction Fraction. 2001, LONDON: Addison-Wesley.

10. Zemanová, M., et al., Pulse current electrodeposition and corrosion properties of Ni-W alloy coatings. Journal of Applied Electrochemistry, 2011. 41(9): p. 1077-1085. 